\title{
Still missing diagnoses
}

\author{
Fernando Peixoto Ferraz de Campos ${ }^{a}$
}

Campos FPF. Still missing diagnoses [editorial]. Autopsy Case Rep [Internet]. 2012;2(3):1-3. http://dx.doi.org/10.4322/ acr.2012.019

Since days of yore, the main purpose of medicine is the patient care, by recognizing the disease and establishing the therapy, aiming to provide relief or cure when possible. Making diagnosis constitutes the key step to achieve this paradigm. In this setting, the medical diagnosis, a complex task, involves specific knowledge and skills, experience, logical reasoning, information processing and pattern recognition. As time passes, intuition, insights and suspicion are added to this process happening at an unconscious level.

The clinical history is the most fundamental tool that triggers the diagnostic process followed by a detailed, careful and precise physical examination. Despite the intellectual diversity of patients, influencing the provision of information through the interpretation of their symptoms, the medical diagnosis can be based on the history alone in more than $70 \%$ of the cases. The ability to focus on important clinical issues and pick up the big picture requires clinicians to separate the wheat from the chaff. Classical presentations of uncomplicated disease are diagnosed by pattern recognition, while complex problems require analytical thought in addition. In this setting, the physician will make use of the complementary laboratory and imaging arsenal.

Some writers divide the diagnostic process in two steps. The first consists on the enumeration of the diagnostic possibilities accompanied by their relative likelihood. In the second step with the addition of each new information of the history and physical examination, the possibilities are being ruled out, and the most likely diagnosis are ultimately being chosen.

In large countries with heterogeneous development areas, like Brazil, depending on the region and the medical workplace or service the interpretation of signs and symptoms may vary and consequently result in different hierarchy of the diagnostic hypothesis. Moreover, this disparity may occur in services of different degrees of medical complexity. An abdominal pain may be differently interpreted in a primary care service of a rural area compared with an emergency service of a tertiary complexity hospital in a cosmopolitan Centre.

Not infrequently, there are situations characterized by ambiguous clinical picture, and others marked by incomplete and fragmentary information, challenging even more the physicians to reach the precise and definitive conclusion.

Physicians are not as perfect as it is expected. All doctors make mistakes, have weakness. Expertise is not a static but dynamic state. Misdiagnosing should not, but still happens, even in what we could call trivial clinical situations. The most frequently missed diagnoses documented in the literature are: cancer, myocardial infarction, pulmonary embolism, aneurysms, infections and appendicitis. These diagnoses are also found in studies on discrepancies between clinical and autopsy. These discrepancies are being kept unchanged in both the rate and in diagnoses over time, despite the technological evolution of the diagnostic armamentarium .

\footnotetext{
a Hospital Universitário - Universidade de São Paulo, São Paulo/SP - Brazil.
} 
This periodic brought to the knowledge, reports of undiagnosed schistosomiasis and strongyloidiasis hyperinfection (N. 2, issues 1 and 2 ). Both constitute examples of high prevalence diseases in our country.

\section{Why misdiagnoses do still occur?}

First of all, as stated above, perfection and precision are qualities that, despite being the target of health professionals, are far from the reality.

In practice, premature closure of the diagnostic process without considering the correct diagnosis as a possibility may represent a common cause of the error. Schiff and colleagues studying 583 diagnostic errors found that failure or delay in considering the diagnosis was the most common failure. Assignment of common benign diagnosis to patients with uncommon serious diseases consists another cause of misdiagnosing. Kostopoulou et al. identified five features of potential diagnostic difficulty: atypical presentation, non-specific presentation, very low prevalence, co-morbidity and perceptual features. The later related to a failure to detect and/or recognize visual or auditory symptoms and signs.

One explanation for many of the misdiagnoses is the misattribution of the presenting symptoms to an obvious explanation or a readily available etiology, like not investigating anemia in young women by explaining it as a result of menstruation. Pre-existing diagnostic label can also hamper the clinician's ability to reformulate the diagnostic problem, looking for alternative possibilities. Difficult or unusual presentations are likely to get missed. In those cases, characterized by a full list of possibilities, how can one decide which possibility to pursue? Simply following the broad list of the differential diagnosis without critical thought, results in unnecessary testing. The experienced clinician first considers the higher probability options and those of greater severity, if left undiagnosed and untreated.

Facing challenging clinical cases, whose diagnosis does not seem obvious, it is noteworthy to verify if the history has been carefully taken. In this case remaking the physical examination, and consult more experienced colleagues is highly recommended.
A missed diagnosis may become clear with hindsight. Relevant information lost or misinterpreted can be found or reassessed before the final diagnosis. Reconsidering or reformulating the initial diagnostic hypotheses can prevent diagnostic errors. Good clinicians regularly review patient data, consider a specific disease in specific circumstances, look beyond the initial diagnosis, revalidate the patterns identified, examine the probabilities and have the courage to question their earlier diagnostic interpretations allowing them to reassign risks and diagnoses.

\section{BIBLIOGRAPHY}

1. Ely JW, Kaldjian LC, D'Alessandro D. Diagnostic errors in primary care: lessons learned. J Am Board Fam Med. 2012;25:87-97. PMid:22218629. http://dx.doi. org/10.3122/jabfm.2012.01.110174

2. Graber ML, Franklin N, Gordon R. Diagnostic error in internal medicine. Arch Intern Med. 2005;165:1493-9. PMid:16009864. http://dx.doi.org/10.1001/archinte.165.13.1493

3. Schiff GD, Hasan O, Kim S, et al. Diagnostic error in medicine: analysis of 583 physician-reported errors. Arch Intern Med. 2009;169:1881-7. PMid:19901140. http://dx.doi. org/10.1001/archinternmed.2009.333

4. Kostopoulou O, Devereaux-Walsh C, Delaney BC. Missing celiac disease in family medicine: the importance of hypothesis generation. Med Decis Making. 2009;29:282-90. PMid:19270107. http://dx.doi.org/10.1177/0272989X08327493

5. Kostopoulou O, Oudhoff J, Nath R, et al. Predictors of diagnostic accuracy and safe management in difficult diagnostic problems in family medicine. Med Decis Making. 2008;28:668-80. PMid:18556634. http://dx.doi. org/10.1177/0272989X08319958

6. Kachalia A, Gandhi TK, Puopolo AL, et al. Missed and delayed diagnoses in the emergency department: a study of closed malpractice claims from 4 liability insurers. Ann Emerg Med. 2007;49:196-205. PMid:16997424. http://dx.doi. org/10.1016/j.annemergmed.2006.06.035

7. Gandhi TK, Kachalia A, Thomas EJ, et al. Missed and delayed diagnoses in the ambulatory setting: a study of closed malpractice claims. Ann Intern Med. 2006;145:488-96. PMid:17015866.

8. Kostopoulou O, Delaney BC, Munro CW. Diagnostic difficulty and error in primary care - a systematic review. Fam Pract. 2008;25:400-13. PMid:18842618. http://dx.doi. org/10.1093/fampra/cmn071

9. Richardson WS, Wilson M. The process of diagnosis. In: Guyatt G, Bhandari M, Tornetta P, Schemitsch EH, 
editors. Users guides to the medical literature. New York: McGraw-Hill; 2008. p. 399-406.

10. Jacob KS. Medical diagnosis: process \& pitfalls. Hindu. 2010 Jan 6 [cited 2012 Aug 9]. Available from: http:/www.hindu. com/2010/01/06/stories/2010010655530800.htm

11. Baerheim $\mathrm{A}$. The diagnostic process in general practice: has it a two-phase strucyure? Fam Pract. 2001;18:243-5. PMid:11356727. http://dx.doi.org/10.1093/fampra/18.3.243
12. Peterson MC, Holbrook JH, Von Hales D, Smith NL, Staker LV. Contributions of the history, physical examination and laboratory investigation in the medical diagnosis. West $\mathrm{J}$ Med. 1992;156:163-5. PMid:1536065 PMCid:1003190.

13. Tavora F, Crowder CD, Sun CC, Burke AP. Discrepancies between clinical and autopsy diagnosis. A comparison of University, Community and Private autopsy practices. Am J Clin Pathol. 2008;129:102-9. PMid:18089495. http://dx.doi. org/10.1309/9M7DFE62RTDKHH4D

Correspondence: Fernando Peixoto Ferraz de Campos

Scientific Editor Autopsy and Case Reports

Assistant Physician of Internal Medicine Division

Hospital Universitário - Universidade de São Paulo, São Paulo/SP - Brazil

E-mail: ffcampos@usp.br 
